\title{
LA MISIÓN DE LA FILOSOFÍA AMERICANA
}

I

La filosofía, de una manera o de otra, ha reflejado siempre la situación del mundo que la origina, y su importancia ha estribado, precisamente, en su capacidad, no sólo para plantear los problemas que la han originado, sino para anticipar soluciones adecuadas a estos problemas. Con el historicismo se ha puesto en claro la importancia de la filosofía en la historia como expresión máxima de los esfuerzos que realiza el hombre para resolver sus problemas de una vez y para siempre, pese a que estas soluciones resulten siempre circunstanciales. Es sintomático el hecho de que ha sido en las etapas más críticas de la historia del mundo occidental, desde Grecia a nuestros días, cuando han surgido los sistemas filosóficos más importantes. Épocas de crisis, de desajuste moral y social. Épocas en las que el hombre pierde los soportes que le daban seguridad. Épocas en las que es menester reajustar el mundo moral y social del hombre; un mundo que ha sido alterado por diversas circunstancias. En cada una de estas épocas han surgido las grandes filosofías que han permitido el reajuste anhelado y, con él, la nueva seguridad.

Nuestra época es, también, una gran época crítica. Una vez más, han sido puestos en crisis valores que hasta ayer parecian firmes y seguros. Las dos guerras mundiales fueron la más brutal expresión de esta crisis. Entre ellas, en el pequeño lapso de paz que separa la una de la otra, surgieron varias filosofías que fueron expresión del desajuste en que había caído la Modernidad. Filosofías que plantearon los grandes problemas que sacudian a nuestro tiempo, pero sin atreverse a plantear soluciones permanentes. $\mathbf{Y}$ no podía ser de otra manera, el estallido de la segunda gran Guerra Mundial mostró, con mayor agudeza, la problemática en que se debatía el mundo, una problemática a la que no se le había encontrado solución. La posguerra ha obligado a un replanteamiento de problemas que aún no han sido resueltos. El mundo actual sigue desajustado moral y socialmente, y este desajuste no ha encontrado, todavía, la filosofía que intente darle solución adecuada. Aún no se pasa de una etapa en la que se exponen los problemas que agitan a nuestro mundo. Una filosofía cuyo tema central, desde el punto de vista moral y social, sigue siendo el de la crisis; pero una crisis frente a la cual no se ha encontrado aún solución, por circunstancial que ésta sea.

La filosofía, y en eso estriba su esencia, aspira siempre a dar soluciones universales a los problemas que se le plantean, por circunstanciales que sean. Sin embargo, nunca como en nuestro tiempo, los problemas han sido más universales. El desajuste que se hace sentir es universal, se plantea a todas 
y cada una de las sociedades que forman nuestro mundo; sociedades estrechamente ligadas entre sí; con ligas que desconocieron sociedades del pasado. Los problemas que se plantean en nuestros días no son ya los problemas propios de una determinada cultura como sucedió en el pasado. La filosofía, fruto de la cultura europea y occidental, se enfrenta ahora a problemas que trascienden los de esta cultura. Y sus soluciones, si han de ser tales, no se pueden ya circunscribir a situaciones locales de esta cultura, por universales que las mismas parezcan. La filosofía tiene ahora que replantearse una serie de problemas tomando en cuenta la realidad que ha originado la cultura occidental en su impacto sobre otros mundos y culturas.

Uno de los grandes problemas de nuestro tiempo se ha expresado, politicamente, con el surgimiento del nacionalismo en los países no occidentales. Nacionalismo surgido al terminar la segunda Gran Guerra, pero que se habia anticipado en varios de los países que forman la América Latina. Nacionalismo que algunas mentes han visto como una peligrosa reacción anti-occidental. ¿Es cierto esto? ¿Las demandas de las nuevas naciones surgidas en nuestra América, Asia, África, Medio Oriente y Oceanía son una amenaza al mundo occidental? ¿No es, más bien, una demanda de ampliación de los bienes que ha originado esa cultura? ¿No es, más bien, una demanda para la auténtica universalización de la misma? ¿La mejor expresión de su universalización? Todos estos pueblos en sus exigencias no piden nada que no esté establecido ya y reconocido dentro de los cánones propios de la cultura occidental. De la cultura occidental han sido tomadas las demandas que ahora se enarbolan frente a los que se consideran sus más legítimos herederos. Europa, los Estados Unidos, el mundo occidental en general, han hablado al mundo de una serie de valores que, al fin, han alcanzado su universalización al ser demandados por otros pueblos considerándolos como propios. Se ha hablado de libertad y dignidad del hombre, de soberania de los pueblos, de los derechos de todos los hombres y pueblos a gozar de los frutos de su trabajo y de la libertad que éstos tienen para dirigir sus destinos. En nombre de estas ideas, de estos valores, los hombres de la mayoría de los pueblos del mundo ofrendaron sus vidas para defenderlos o realizarlos. ¿Qué de extraño tiene que ahora estos pueblos e individuos reclamen la universalización de su vigencia? Estos pueblos y hombres reclaman a sus maestros, los pueblos occidentales, lo que ellos les enseñaron: respeto a su soberanía, derecho a dirigir sus destinos, derecho a disfrutar de sus riquezas naturales y al esfuerzo de su trabajo. Tales exigencias no son, ni pueden ser consideradas como una amenaza a la cultura occidental, sino como un llamado a la vigencia universal de la misma.

¿Qué es, entonces, lo que en verdad amenaza a esta cultura y la hace sentir en crisis, la crisis que ahora se expresa en su filosofía? Pura y simplemente el viejo espíritu exclusivista que, paradójicamente, ha formado parte del mismo espíritu que ha hecho posible la cultura universal más auténtica. 
Esta cultura, originada en el Occidente, no es ya obra de europeos u occidentales. $O$, en otras palabras, la occidentalización ha trascendido sus propias matrices. Su obra es ya obra de todos los pueblos y hombres que han recibido su impacto y la han transformado en algo propio. $Y$ esto lo podemos decir, no sólo de valores propios de la cultura occidental de carácter social y político, como las ideas de libertad, justicia social, democracia y otros muchos más, sino también de otros valores más personales de esta cultura en el campo artístico, literario, filosófico, científico.

Así, en la estrechez de miras, en el exclusivismo que anima al hombre, se encuentra la mayor amenaza a su propia obra y sigue planteando el principal de los problemas a resolver, ahora como ayer, por la filosofía. Espíritu exclusivista que se niega a reconocer en otros hombres o pueblos derechos que antes ha reclamado para sí. Exclusivismo que hace de la ciencia de nuestro tiempo, llamada a ampliar las posibilidades de la humanidad, un simple instrumento al servicio de unos cuantos intereses y unos cuantos hombres. Es el mismo espíritu que hace de la energía atómica, y de la fuerza que impele los cohetes que vencen la gravedad de la tierra, simples instrumentos para amedrentar a otros hombres, instrumentos de dominio terrestre. Fuerzas ganadas por el hombre a la naturaleza que lejos de servir para ampliar sus posibilidades, sólo le sirven para disputarse un mundo que le resulta cada vez más estrecho. Esto es, fuerzas que no se diferencian de lo que fuera la cachiporra para el hombre primitivo. Fuerzas al servicio de la destrucción del hombre por el hombre.

Es el mismo espíritu el que hace que unos hombres nieguen a otros lo que reclaman para sí. Es el espíritu que aún se hace patente en las relaciones que mantienen los viejos pueblos occidentales y sus herederos con los pueblos que, por obra de su propio impacto, se han transformado en nuevas naciones. Espíritu que niega humanidad a otros hombres, o al menos, la pone en duda. Es este espíritu el que impide la más extraordinaria universalización de una cultura, universalización nunca vista. $Y$ es esta universalización y el espíritu estrecho que trata de frenarla, lo que provoca la crisis que ahora se expresa en el campo cultural y se refleja en la filosofía de nuestro tiempo.

\section{II}

¿Cuál debe ser el papel del filósofo frente a este mundo? ¿Cuál es su responsabilidad ante el mundo actual?

En mi opinión, una tarea de ajuste. Deben ser ajustados los intereses concretos de los pueblos y hombres que han hecho posible la cultura occidental con la realidad que su acción ha originado. El espíritu exclusivista que permitió la hegemonía de la cultura occidental en el resto del mundo no occidental está ahora en crisis y exige un reacomodo a la realidad que él 
mismo ha originado. E1 hombre que hizo posible esta cultura, que la ha heredado se encuentra ahora frente a un mundo que trasciende las limitadas metas de sus creadores. Un mundo frente al cual los limitados intereses que la hicieron posible resultan, ahora, impedimentos para su vigencia y desarrollo. La vigencia de esta herencia depende de la capacidad del hombre para crear las condiciones de posibilidad que permitan su ampliación $\mathrm{y}$, por ende, su vigencia entre hombres y pueblos que hasta ayer la consideraban como ajena y que ya la reclaman como suya.

Lo que ahora está en juego, no es tanto la existencia de la cultura, entre cuyos frutos se encuentra la filosofía, sino la posibilidad de su universalización. La principal preocupación del filósofo contemporáneo deberá ser la de dar estímulo a las condiciones que permitan la universalidad de los valores que originó la cultura occidental. Estímulo mediante una tarea reeducativa que muestre a las nuevas generaciones los alcances de la universalización de la cultura occidental. Reeducación que permita al hombre ver en otros hombres semejantes con los que tiene que colaborar en la realización de una tarea que ya es común a todos los hombres. Sin exclusivismo alguno, haciendo a un lado todo espíritu discriminatorio racial, económico, político, religioso o social. Reeducación que permita ver a los otros hombres como semejantes y no como opositores; no considerar ya como enemigo a todo el que quiera participar en una tarea que no tiene por qué ser exclusiva de un grupo. Reeducación que muestre al hombre que el reconocimiento de la humanidad de otros hombres lejos de amenazar a la cultura occidental servirá para su más auténtica universalización. La cultura occidental, y la filosofía que la expresa, ha puesto el acento en lo humano como valor supremo. En lo humano sin discriminación racial, religiosa, política o cultural; y es, precisamente, este humanismo el que ahora trasciende las fronteras en que se originó y es reclamado universalmente.

Para la América Latina, para sus pensadores y filósofos, esta preocupación no es nueva. En esta América, por razones históricas bien conocidas, se han planteado y se plantean problemas semejantes a los que ahora se plantean entre la cultura occidental y los pueblos no occidentales que han recibido su impacto. Heredero de dos mundos, el hombre de esta América se ha resistido a renunciar a uno de ellos anulando el otro. Eclécticamente se ha planteado el problema de occidentalizar la América, o americanizar la cultura heredada. Un problema semejante al que ahora se plantean otros pueblos de nuestra ya estrecha Tierra. Un problema que se plantea al mismo Occidente: ¿occidentalización del mundo o universalización de la cultura occidental? Imitación o asimilación, parece ser la disyuntiva. Imposición de puntos de vista, $o$ intereses, ajenos a una determinada realidad; o asimilación y conjunción de ellos a la realidad dada. En nuestra América la occidentalización, o europeización, sin más, nunca dio resultado. Por eso se ha elegido, 
en nuestros días, la segunda vía, la de la americanización. de la cultura heredada. Esto es, la búsqueda de su vigencia en realidades para las cuales no está hecha. El latinoamericano ha terminado, sin abandonar su afán de formar parte de una cultura de la que se sabe heredero, por reconocer la realidad que le es peculiar para adaptar a ella sus aspiraciones de occidentalización. Se busca ahora la conciliación de las expresiones de la cultura de que se sabe hijo con la realidad ineludible en que también se ha formado. $Y$ así sin dejar de ser americano es también un miembro activo de la cultura occidental.

Este mismo problema se plantea ahora desde un punto de vista más amplio, como hemos anticipado. $Y$ en él el filósofo latinoamericano puede aportar sus mejores experiencias. Se trata ahora, insistimos, de reajustar la cultura occidental a las circunstancias que la acción de sus creadores han originado. Ajuste que ponga término a la situación de tirantez y crisis en que vivimos.

\section{III}

Si algo caracteriza a la filosofía en América es su preocupación por captar la llamada esencia de lo americano, tanto en su expresión histórica y cultural, como en su expresión ontológica. Esto no quiere decir que no exista un filosofar más preocupado por los grandes temas de la filosofía universal. Desde luego existe $y$, en nuestros días, son muchas las figuras que se destacan en el mismo en América. Sin embargo, lo importante para comprender mejor la historia de nuestra culturà es este filosofar que ha hecho de América el centro de sus preocupaciones. Este filosofar, a diferencia de la llamada filosofía universal, tiene como punto de partida la pregunta por lo concreto, por lo peculiar, por lo original en América. Sus grandes temas los forman preguntas sobre la posibilidad de una cultura americana; preguntas sobre la posibilidad de una filosofía americana; o preguntas sobre la esencia del hombre americano.

No preocupa a nuestros pensadores, filósofos y ensayistas de lo americano, lo universal, sino lo concreto, lo que caracteriza a la cultura americana, lo propio del hombre americano. La originalidad de América y del hombre americano es el tema de este pensamiento. Tema que nunca preocupó o pudo preocupar a la llamada filosofia universal que partía, precisamente, de este supuesto de su universalidad. Los grandes filósofos griegos, medievales, modernos o contemporáneos de la cultura europea, nunca se habian preocupado por lo original, lo peculiar de sus culturas, ya que consideraban a éstas, y al hombre que las creaba, lo universal por excelencia. En estos últimos años, y como consecuencia de una serie de crisis, la filosofía europea ha centrado, también, su preocupación en torno a lo concreto, aceptando la circunstancialidad de su filosofar. Expresiones de este filosofar lo son el histori- 
cismo y el existencialismo. Pocas expresiones hay de esta nueva actitud de la filosofía europea que la pinten mejor con lo trágico que la misma encierra, como las palabras de Jean Paul Sartre en uno de los personajes de sus novelas: "Era tan natural ser francés... Era el medio más sencillo y económico de sentirse universal. Eran los otros... quienes tenían que explicar por qué mala suerte o culpa no eran completamente hombres. Ahora Francia está tendida boca arriba y la vemos como una gran máquina rota. Y pensamos: era esto un accidente del terreno, un accidente de la historia. Todavía somos franceses, pero la cosa ya no es natural. Ha habido un accidente para hacernos comprender que éramos accidentales."

Pues bien, si algo caracteriza a la preocupación por lo americano es, precisamente, esta conciencia de la accidentalidad de nuestra cultura y nuestro ser. La pregunta por la peculiaridad de la cultura y el hombre en América tiene como punto de partida esta conciencia de lo accidental. Y, precisamente, lo que se presenta como peculiar a la una y al otro en los análisis que se le hacen es esa misma accidentalidad. El americano, a diferencia del europeo, nunca se ha sentido universal. Su preocupación ha sido, precisamente, una preocupación por incorporarse a lo universal, por insertarse en él. Y, aunque parezca una paradoja, esa misma pregunta por lo que le es peculiar, es una pregunta que tiende al conocimiento de lo que tiene de universal, esto es, de común con todos los hombres. La peculiaridad buscada es la de su humanidad, la de aquello que le hace ser un hombre entre hombres; no el Hombre por excelencia, sino el hombre concreto, el hombre de carne y hueso que es, y sólo puede ser, el hombre en cualquier lugar del mundo, con independencia de su situación o, mejor dicho, a causa de esa misma situación, que es lo peculiar a todos los hombres. Este sentido de la peculiaridad del hombre en América, que acaba siendo lo propio de todos los hombres, lo ha hecho patente Octavio $\mathrm{Paz}$ en su magnifico ensayo titulado $\mathrm{El} \mathrm{Laberinto} \mathrm{de}$ la Soledad: "Estamos al fin solos. Como todos los hombres. Como ellos vivimos el mundo de la violencia, de la simulación y del ninguneo: el de la soledad cerrada, que si nos defiende nos oprime y que al ocultarnos nos desfigura y mutila. Si nos arrancamos esas máscaras, si nos abrimos, si, en fin, nos afrontamos, empezamos a vivir y pensar de verdad. Nos aguardan una desnudez y un desamparo. Allí, en la soledad abierta, nos espera también la trascendencia: las manos de otros solitarios. Somos, por primera vez en nuestra historia, contemporáneos de todos los hombres."

De esta manera Sartre, el francés, y Paz, el mexicano, el europeo y el americano, se encuentran por la vía de lo accidental; una accidentalidad, circunstancialidad, común a todos los hombres. Lo concreto, la diversidad de lo concreto, lejos de hacer imposible la esencia de lo humano lo hace real. Muestra lo que de humano tiene cualquier hombre de la Tierra. Hace patente esa humanidad que la pretendida universalidad del pensamien- 
to europeo negaba a otros hombres. Un nuevo tipo de universalidad de lo concreto en cuya cuenta, hasta recientes fechas, ha caído el europeo; un tipo de universalidad peculiar, por el contrario, el americano. De aquí también esa otra expresión del pensamiento americano que, sin conciencia de lo anterior, podría parecer absurda por parecer en contraposición con esa preocupación por la peculiaridad de lo americano partiendo, precisamente, de la conciencia de su accidentalidad, conciencia que, por el contrario, faltaba al europeo, a pesar de esa su presunción de hombre universal. Este hombre, el europeo, lejos de ser un hombre universal, al presumir de tal, no ha hecho otra cosa que comportarse como un provinciano. "Pueblos magistrales -dice Alfonso Reyes refiriéndose a los europeos- que, por bastarse a sí propios, han vivido amurallados como la antigua China, y mil veces nos han dado ejemplo de la dificultad con que salen de sus murallas." Otro pensador, José Ortega y Gasset, europeo por sus pretensiones, pero más cercano a la América por pertenecer a una cultura tan marginal a la europea como la nuestra, la española, decía del europeo: "En los últimos siglos el hombre europeo ha pretendido hacer historia en un sentido objetivamente universal. De hecho, siempre parecerá al hombre que $s u$ horizonte es $e l$ horizonte y que más allá de él no hay nada... Esto es, en efecto, lo que ha acontecido con la ciencia histórica europea durante tres siglos: ha pretendido deliberadamente tomar un punto de vista universal, pero, en rigor, no ha fabricado sino historia europea." "Porciones gigantescas de vida humana, en el pasado y aun en el presente, le eran desconocidas y los destinos no europeos que habian llegado a su noticia eran tratados como formas marginales de lo humano, como accidentes de valor secundario, sin otro sentido que subrayar más el carácter sustantivo, central de la evolución europea." Pero hoy, agrega Ortega, "hoy empezamos a advertir cuánto hay de limitación provinciana en ese punto de vista".

En abierta contraposición con la estrechez de miras del europeo, está la del americano. En nuestros pueblos, dice José Vasconcelos, podéis tomar a un niño de Cuba o de Colombia y preguntarle por los hombres que cree son los más grandes de la historia "y os dirán: Sócrates, Platón, el Dante...". "Hacedle la misma pregunta a un niño norteamericano, y dirá: Edison, Lincoln o Henry Ford. Lo mismo acontecerá con el francés y de otras nacionalidades. $\mathrm{Y}$ es que en filosofía esos pueblos están llenos de prejuicios de raza y no prescinden de englobar a personalidades nacionales, no tienen la libertad espiritual de nuestra raza, que no arrastra prejuicios." Vasconcelos llama a esta raza formada por los pueblos de la América Ibera o América Latina, Raza Cósmica, raza universal. Los anglosajones, como podrá verse por la cita, son incluidos dentro de la cultura europea conteniendo todas sus limitaciones. La de los pueblos iberoamericanos está destinada a ser una raza cósmica precisamente porque no tienen prejuicios de raza, esos prejuicios que 
determinan la actitud cultural estrecha de los europeos. Desde la Independencia, nuestra América Latina aspiró a lo universal y se hizo "en el bando latino lo que nadie pensó hacer en el Continente Sajón”. "Allí siguió imperando la tesis contraria, el propósito confesado o tácito de limpiar la Tierra de indios, mongoles y negros para mayor gloria y ventura del blanco."

De esta manera se pasa de lo peculiar a lo universal. Lo peculiar en la América Latina resulta ser lo universal. "Yo creo - dice Vasconcelos en otros de sus libros- que corresponde a una raza emotiva como la nuestra sentar los principios de una interpretación del mundo de acuerdo con nuestras emociones. Ahora bien, las emociones se manifiestan, no en el imperativo categórico ni en la razón, sino en el juicio estético, en la lógica particular de las emociones y la belleza." Una cultura, apoyada en las emociones estéticas, piensa Vasconcelos, se sobrepondrá a lo puramente físico y limitativo. Surgirá una quinta raza, la cósmica, raza síntesis, "con la sangre de todos los pueblos" y con su genio, y tendrá su asiento "en la parte ibérica del Continente Americano". Este tipo de conciencia de lo universal, no es otra cosa que conciencia de lo humano. El americano, limitado, marginal, ha captado en estas limitaciones lo que tiene de común con todos los hombres, lo que tiene de universal. Por ello puede decir como Alfonso Reyes: "Somos una parte integrante y necesaria en la representación del hombre por el hombre. Quien nos desconoce es un hombre a medias." Pero, cha sido siempre captada esta humanidad en el americano, concretamente en el iberoamericano?

Esta es la misión que a sí misma se ha impuesto la filosofía en esta América. De alli esa su central preocupación por describir y conocer el ser del hombre americano y su cultura. Conocimiento que no tiende, como equivocadamente se ha pensado, a destacar peculiaridades que hagan del americano un ente fuera del mundo, del hombre, fuera de la humanidad, sino, por el contrario, peculiaridades que lo incorporen. Su problema, el problema de la filosofia en América, es precisamente la conciencia de que su existencia es una existencia marginal. Ante Europa, especialmente ante la Europa moderna, no es otra cosa que un mundo telúrico, primitivo, sin espíritu. Las mentes europeas que se han acercado a América no han podido ver en ella otra cosa que primitivismo. América, para estas mentes, sigue siendo un Mundo Nuevo, mundo por hacer, mundo primitivo. De aquí la reacción de nuestros pensadores ante el regateo de que es objeto su mundo. Este regateo, este poner en duda la plena humanidad del americano ha hecho reaccionar a éste mostrando cómo esas peculiaridades, ese modo de ser que parece propio del americano, es un modo de ser universal, propio de cualquier hombre en situaciones semejantes. El americano no es ni más ni menos que un hombre. 